\title{
Policy Tool Model and Its Application in the Governance of Characteristic Towns
}

\author{
Dameng Luo, Yun Zhang \\ Sichuan University of Arts and Sciences, Dazhou, China \\ Email: zhuiqiu1234@163.com
}

How to cite this paper: Luo, D. M., \& Zhang, Y. (2020). Policy Tool Model and Its Application in the Governance of Characteristic Towns. Open Journal of Social Sciences, 8, 232-244.

https://doi.org/10.4236/jss.2020.87019

Received: June 26, 2020

Accepted: July 19, 2020

Published: July 22, 2020

Copyright $\odot 2020$ by author(s) and Scientific Research Publishing Inc. This work is licensed under the Creative Commons Attribution International License (CC BY 4.0).

http://creativecommons.org/licenses/by/4.0/ (c) (i) Open Access

\begin{abstract}
Policy tools are the mechanism by which policy ideas and policy goals are transformed into specific policy actions, the bridge connecting goals and results, and the necessary path for policy implementation. The choice of policy tools will be affected by multiple factors such as policy environment, policy objectives, policy objects, governance structure, and tool characteristics. And constructed a policy tool selection model. Based on this theory, it analyzes the selection of policy tools for characteristic towns in the fields of planning, comprehensive development, operation, investment and financing. The article believes that the policy tools that can be used in the planning stage of characteristic towns are: deregulation, decentralization, families and communities, social organizations, public participation, contract outsourcing, etc. The policy tools that can be used in comprehensive development are: deregulation, financial allocation, contract outsourcing, public-private partnership, etc. The policy tools that can be used during the operation phase are: regulation and deregulation, franchising, privatization, user payment, government purchases, social forces, and public participation. The policy tools that can be used in investment and financing are: bonds, funds, product crowdfunding, financial leasing, PPP financing, etc.
\end{abstract}

\section{Keywords}

Characteristic Towns, Governance, Policy Tools

\section{Research Origin and Analysis Perspective}

\subsection{Research Origin}

The new era of socialism with Chinese characteristics is both an era of "co-construction, co-governance and sharing" and an era of quality and efficiency. Social governance in the new era requires precise positioning and refined operations at 
the level of governance concepts, goals, structures, processes, mechanisms, tools, etc., in order to further promote the lean innovation of the governance pattern and the upgrading of governance quality. The construction of "characteristic towns" promoted by "new concepts, new mechanisms and new carriers" in Zhejiang Province was the beginning of the governance of towns with Chinese characteristics. In October 2016 and July 2017, the Ministry of Housing and Urban-Rural Development, the National Development and Reform Commission, and the Ministry of Finance announced the first batch (127) and the second batch (276) of towns with Chinese characteristics. The construction movement is culminating, and the provinces and cities have followed suit. According to statistics, the total number of towns with national and local characteristics is nearly 1900. Characteristic towns are based on the new concepts of innovation, coordination, green, openness and shared development, and promote the integration of production, life and ecology. On the basis of digging out industrial characteristics, cultural heritage and ecological endowments, a four-in-one characteristic spatial settlement of industry, city, people and culture is formed. As a new concept of urbanization construction, it not only carries the mission of beautiful rural construction and rural revitalization, but also an important measure to promote the integration of urban and rural development in the new era of socialism with Chinese characteristics. The governance model, governance pattern and governance quality of characteristic towns will form a powerful demonstration effect and constitute the key to the success or failure of China's new urbanization movement. However, at present, the construction of characteristic towns is faced with dilemmas and difficulties such as inaccurate positioning, low quality, unclear characteristics, emphasis on construction rather than management, and prominent system and mechanism obstacles, which have seriously affected the function of the characteristic town and its original intention. Therefore, promoting the reform of the governance mechanism of characteristic towns is not only required by the times, but also by mission. This article focuses on the selection of policy tools in the stages of planning, comprehensive development, operation, investment and financing of characteristic towns to promote the good development of characteristic towns at the level of policy construction.

\subsection{Literature Review and Analysis Perspective}

Governance, as a theoretical research framework that emerged with the new public management movement in the 1990s, "it is popular in many contexts" (Jessop, 1999), and has formed many branches of theoretical research, such as global governance, public governance, and networking Governance, holistic governance, digital governance, civic governance, good governance, collaborative governance, participatory governance, democratic governance, precision governance, etc. With the rise of the creation of characteristic towns, the governance of towns has gradually attracted the attention of academic circles. For example, $\mathrm{Hu}$ Xiaowu (Hu, 2017) analyzed the problem of governance innovation in cha- 
racteristic towns, and proposed that "characteristic towns need to innovate in governance concepts, governance structures and models. It is necessary to fully tap the resources and potential of 'stakeholders' to enhance the participation of all parties. Enthusiasm". Yao Shangjian (Yao, 2017) based on the policy issues of characteristic towns, analyzed the problem of governance integration in urbanrural integration. He proposed that "the construction of characteristic towns initiated by local governments is not only a first attempt of urbanization policy, but also governance among different local governments. Therefore, the construction of characteristic towns "should not only be included in the overall national urbanization strategy, but also respect the positive results of local policy innovation, and realize the functional integration of industrial transformation, population introduction and cultural inheritance in the urban-rural governance merger.". Shi Yungui (Shi, 2017) also proposed the construction of characteristic towns, "the old ideas and methods cannot be followed, and must be practiced in exploration and perfected in innovation", and then build "characteristic towns of co-construction, co-creation, sharing and co-governance". Some scholars have studied the policy supply of characteristic towns from the perspective of policy analysis. Zhang Hongyuan (Zhang \& Zhang, 2016) took Leshui Township in Chun'an County as an example to analyze the policy orientation of Zhejiang characteristic towns; Xie Wenwu and Zhu Zhigang (Xie \& Zhu, 2016) took Yuhuangshannan Fund Town as an example to analyze the system and policy innovation created by characteristic towns; Zhuo Yongliang (Zhuo, 2016) analyzed the innovation of government policy supply from the perspective of planning and construction of characteristic towns; Feng Kui (Feng \& Huang, 2016) analyzed the policy practice and policy focus of the construction of Zhejiang characteristic towns. Some scholars have introduced the theory of precise governance into the study of characteristic towns. Min Xueqin believes that in this "characteristic town movement" in China, we should say goodbye to the mode of extensive operation. From the parallel design and development to the overall construction and life sharing, every link must be embedded in the theory and practice framework of precision governance, and then build a demonstration of precision governance from demand to supply in characteristic towns (Min, 2016). Liu Jianhui gave a detailed introduction to the refined social governance model of national towns in Guzhen Town, Zhongshan City (Liu, 2017). But overall, the research on the governance of characteristic towns is still inadequate. Although some scholars have paid attention to the policy issues of characteristic towns, most of them analyze the policy supply, and the implementation and policies of the governance in characteristic towns. The choice of tools is rarely involved. Governance, as a new paradigm different from the traditional government management model, puts more emphasis on the targeting ability of policies, the ability to transform policy objectives into specific policy actions, and the ability to accurately identify and solve social and public problems, the choice and design of governance tools or policy tools And application is conducive to achieving 
accurate identification of problems, successful docking of goals and needs, and scientific supply of policies. In the construction of characteristic towns, the introduction of a policy tool perspective can promote the precision of the governance of characteristic towns and enhance the effectiveness of town governance.

\section{Types of Policy Tools and Selection Models}

Policy instruments, also known as governance instruments, the core issue of their research is "how to transform policy intentions into management behaviors, and transform policy ideals into policy reality" (Chen \& Xue, 2007), it is the concept of policy The mechanism for transforming policy objectives into specific policy actions is a bridge connecting objectives and results, and is a necessary path for policy implementation. "Policy programs can only be effectively implemented through appropriate policy tools to achieve the ideal state of policy design" (Chen, 2011). The choice and application of policy tools is the key to whether policy goals can be achieved. Appropriate policy tools are conducive to improving policy programs, enhancing the quality and effectiveness of policy implementation, and solving complex policy issues. In addition to the relevant factors such as the policy itself and the policy environment, the failure of policy also means that the means and mechanism of policy implementation, that is, the inappropriate selection of policy tools, are also extremely important causes. Therefore, the choice of policy tools will be related to the success or failure of policies. After the policy is determined, "the choice of policy tools becomes more important as knowledge to improve execution performance" (Chen, 2011). However, how to divide the types of policy tools, build a policy toolbox, and form a "treasure bag" for actors to use or potentially use, and open the toolbox according to different goals and policy issues, and select the appropriate policy tool or The combination of tools is an important problem in the policy process.

Scholars divide policy tools into different types according to different dimensions. For example, MacDonnell and Aymore divided policy tools into command tools, incentive tools, capacity building tools, and system change tools according to their desired goals (Peters \& Van Nispen, 1998). According to the degree of government involvement in the supply and service of public goods, Hollet and Ramesh divided policy tools into three types: voluntary tools, mixed tools, and mandatory tools (Howlett \& Ramesh, 1995). Domestic scholars Zhang Chengfu and Dang Xiuyun also divided the direct provision, entrustment, contract outsourcing, subsidies or subsidies, vouchers, franchising, government sales, self-assistance, voluntary services, market operation according to the degree of government intervention. 10 types of policy tools (Zhang \& Dang, 2007). According to the development requirements of modern management technology, Chen Zhenming divided policy tools into three categories, namely market-based tools, business management techniques and socialized means (Chen, 2004).

The above classification of policy tools is undoubtedly scientific and provides us with a toolbox to choose from, but they also ignore the differences in the 
choice of policy tools in the governance of social issues or policy issues by different policy subjects. The subject of is limited to the government, but "other subjects can also have their own policy tools" (Chen, 2004). Governance, as an activity supported by a common goal, advocates multi-agent cooperation and co-governance. The government, market, and society handle public affairs and resolve policy issues through cooperation, consultation, and partnership. Based on this, following the construction of the cooperative governance mechanism of government, market, and society, and according to the different policy undertakers, the policy tools can be divided into social tools (family and community, volunteer services, social organizations, public participation), market tools (Privatization, user payment, contract outsourcing, property rights transactions, franchise), government tools (regulation and deregulation, decentralization and decentralization, direct provision, taxation, subsidies, internal market, loans, investment and financing, financial allocation), Mixed tools (public-private partnership), etc.

How to choose the appropriate governance tool from the policy toolbox? Hollet and Ramesh constructed a model of policy tool selection based on the two variables of national capacity and complexity of the policy subsystem. The characteristics of national capabilities and policies themselves are undoubtedly important variables that influence the choice of policy tools, but they also ignore the possible impact of the characteristics of other governance subjects and policy objects on the choice of tools. From the perspective of governance, Ringling constructed the relationship framework between the types of governance models and the choice of policy tools. The division of the governance model is based on the state, especially the role of the central government. The relationship model between the governance model and policy tools has a strong government or state-centered color, and the autonomy of other governance actors is intentionally obscured, too.

Policy tools are the specific means and methods adopted by the policy subject to implement the policy plan to the policy object in order to achieve the policy objectives. Therefore, the choice of policy tools will be affected by factors such as the policy environment, policy objectives, governance model, governance object, and the characteristics of the tool itself. The environment in which the policy is implemented will affect the unification or diversification of the governance model. Generally speaking, the political environment is tense The period will lead to the expansion of political power and reduce the diversified development space of governance subjects. The unified governance of the government will dominate. On the contrary, the contraction of political power will be beneficial to the diversification of governance subjects. "Policy objectives set the direction for policy tools and provide a criterion for judging the effectiveness of policy tools" (Chen, 2004). The composition and complexity of policy objectives also affect the governance model. The more complex the policy objective system, the more necessary Cooperation of multiple subjects. Similarly, the different characteris- 
tics of governance objects mean that different governance models need to be selected. The choice of policy tools also needs to consider the characteristics of the policy tools themselves, "Each tool has its scope of application and has its value, but it cannot cure all diseases" (Chen, 2004). Therefore, the selection model of policy tools , according to different problems (governance objects), different objectives, different governance models, and different policy environments, after considering the characteristics of each tool, The governance subject chooses different governance tools from the toolbox. The policy environment is relatively stable and has constant characteristics due to the influence of the national policy orientation; the scope of the tool itself, its characteristics, advantages and disadvantages will vary with the implementation environment and the role of the target, but It is a dependent variable and does not automatically affect the choice of policy tools. Therefore, policy objectives, governance structures and governance objects have become important variables that influence the choice of tools. After the policy objectives are determined, governance structures and objects have a crucial role.

In summary, this paper believes that the choice of policy tools will be affected by multiple factors such as the policy environment, policy objectives, policy objects, governance structure, and tool characteristics. It can be divided into government, market, society, and mixed from the perspective of different policy undertakers. There are four types of policy tools, such as type, and different policy tools are selected according to different policy environments and policy objectives.

\section{The Choice of Policy Tools in the Governance of Characteristic towns}

The characteristic town "non-town non-district" has a clear and unique positioning in terms of industrial structure, planning layout, production and life. Therefore, the governance of characteristic towns also includes comprehensive development, planning, operation, investment and financing, etc. Own characteristics. To achieve the characteristics of town governance, it is necessary to introduce the theory of policy tools and choose appropriate governance tools to enhance the ability to accurately identify problems, target the policy, and implement policy, improve the quality and effectiveness of town governance, and then promote characteristics The town's industry is "special and strong", its function is "union and integration", its form is "small and beautiful", and its mechanism is "new and live". It has embarked on a new small town with distinctive characteristics, the integration of industry and city, and benefiting the masses.

\subsection{Policy Tools in the Preparation of Special Town Planning}

Planning is a strategy, tactic and blueprint. Doing a good job in planning and preparation is an important prerequisite for the development of characteristic 
towns. Without good planning, characteristic towns will be properly positioned and fall into the quagmire of homogenization and real estate. Characteristic towns have the characteristics of production, life, ecological integration and development, and "industry, city, people, and culture". In the process of planning, industrial characteristics, humanistic heritage, and ecological endowments should be fully explored. The form and mechanism highlight its characteristics. Therefore, the development of characteristic towns needs to do a good job in the planning and planning of the following aspects: industrial layout, rural pastoral environment, overall pattern, construction intensity and neighborhood shape, commercial and public service facilities, roads and transportation facilities, green spaces and open spaces, Town appearance, traditional culture protection and inheritance, etc. The planning of a special town is a major event concerning the interests of all residents in the area. It should adhere to the concepts of government auspices, public participation, and social collaboration, and create a unique space that is livable, industry, and travelable. In planning, the government should accurately position its role. Hosting is not the dominant one. It can't be done by making decisions on the head. It should appropriately deregulate, decentralize, and introduce market mechanisms to encourage all parties, such as families and communities, and social organizations. Experts, the public, etc. participate in the planning and preparation work, and can even explore outsourcing the town planning and preparation to private companies, scientific research institutes, and social organizations with appropriate qualifications through bidding and other methods. After the expert plan and public hearing pass, The government pays according to the contract agreement. The policy tools applied at this stage mainly include government tools such as deregulation and decentralization, social tools such as families and communities, social organizations, public participation, and market-based tools such as contract outsourcing. Only the simultaneous use of various tools such as government, market, and society can ensure the scientific and reasonable planning of special towns, and find a town construction path that is suitable for the long-term development of special towns and is in line with its historical, ecological, and cultural environment. In order to truly realize the co-construction and co-governance and sharing of characteristic towns, promote the coordinated development of production, life and ecology, and better serve the community.

\subsection{Policy Tools in the Comprehensive Development of Characteristic Towns}

The comprehensive development of characteristic towns mainly includes five core levels, namely primary land development, secondary real estate development, industrial project development, industrial chain integration development, and urban construction development. The first-level development of land in characteristic towns "is mainly a process in which the specific implementation entities organized and determined by the government through entrustment, bid- 
ding, etc. requisition, demolition, resettlement, compensation, and infrastructure construction and land leveling of state-owned land and collective land" (Zhou \& Zhang, 2018). The first-level development of land in characteristic towns can be mainly through two models. One is the BT model, that is, the "construction-transfer" model. During the first-stage development of land in characteristic towns, the government and the market with the cooperation of governance entities, the government relaxes the control of the land market, and the land reserve agency outsources the first-level development of the land through contract leasing and competitive bidding. The winning bidder conducts investment and financing, organizational construction, and management in accordance with the contract signed with the government after the work is completed and the project is completed, the government uses the financial appropriation to redeem the project facilities and other public goods prepared by the contractor according to the agreement. The policy tools used in this model are: government tools such as deregulation, fiscal appropriation, and market-based tools such as contract outsourcing. The second is the land resource compensation model, that is, "the land reserve agency determines through entrustment or bidding that enterprises with corresponding qualifications are responsible for the infrastructure construction of the planned reorganization area. After completion, a certain area of land is used as the consideration for land development by the enterprise. Model" (Zhou \& Zhang, 2018). The policy tools used in this model are: contract outsourcing and subsidies. Secondary property development, that is, the process of land users selling and renting newly built real estate through development and construction. The policy tools used at this stage are: privatization and deregulation. Industry is the core of the development of characteristic towns. Without industry, characteristic towns lack the foundation for in-depth and sustained development. Through the cultivation of industry, brand building and market expansion, characteristic towns can realize the integrated development of the industrial chain and establish a complete industrial chain. In the two stages of industrial project development and industrial chain integration development, the role of government guidance and market players should be fully utilized, and efforts should be made to create a special industry cluster ecosystem. The policy tools at this stage are: deregulation, decentralization, and franchising. Urban construction and development, including urban services, urban management, and construction of urban supporting projects such as banks, schools, and hospitals. This stage can be implemented by using public-private partnerships and other mixed policy tools, such as the LBO/BBO model (lease/purchase-construction-operation),private enterprises renting or acquiring basic settings from the government, and the government granting franchise rights; BTO model (Construction-Transfer-Operation), private sector financing, design, and construction of infrastructure. After completion, transfer ownership to the public sector and be authorized to operate infrastructure components within a specified period of time. Users can be charged; BOO model (construction-Own-operate), the 
private sector finances, establishes, owns, and permanently operates infrastructure components under the supervision of the public sector.

\subsection{Policy Tools in the Operation of Characteristic Towns}

Operation is the key to the construction of characteristic towns. Good planning requires an effective operation mechanism to implement and land. Planning and operation cannot be neglected. If planning is more important than operations, the planning will be suspended and become a flower in the moon. Planning and project implementation will also lack guidance and direction. After the planning of the characteristic town is completed, the operation is extremely important. The problems in the construction of the characteristic town often appear in the operation link. Operation is the planning, organization, implementation and control of the operation process. The characteristic towns nurtured and developed under the conditions of the market economy should be adapted to the requirements of the market economy and establish a town operation system in which multiple subjects participate. All along, the government has always been in a dominant position in the construction of cities and towns in China. It is the promoter and core operating body of urban construction. It is both a planner and an operator, both an athlete and a referee. Operators, managers, supervisors and other roles in one. In this mode, the government is solely responsible for the construction and operation of the town construction, or the government entrusts other government departments or state-owned enterprises to operate through the internal market. The government has absolute control. Although it is conducive to the rapid construction and development of the town, the operating cost Higher, the government's financial pressure is greater. In the new era of socialism, an operating mechanism of government guidance, market operation, enterprise subject, and social participation should be established, and the government-led model should be transformed into a government-enterprise linkage development model or an enterprise-led-government supervision model. In the joint development model between the government and enterprises, the BOT form (constructionoperation-transfer) can be adopted. "The government is responsible for the positioning, planning, infrastructure and approval services of the town, and through market-oriented methods, the introduction of social capital for investment and construction is promised. Investors have the right to operate within a certain period of time, and then return it to the government after expiration" (Lin, 2017). This model helps the government to relieve financial pressure and solve the financial difficulties in the operation of the town through the cooperation between the government and the capital market. The enterprise-led-government supervision model means that in the operation and management of characteristic towns, "an enterprise or a number of enterprises jointly complete investment and construction operations, obtain revenue through government purchases or user payments, and are subject to government management and supervision" (Lin, 2017). This model can be operated in the form of BOO (construction-ownership-opera- 
tion), and it can also effectively solve government financial problems and activate market vitality. In addition, in the operation of the town, social forces and public participation are also indispensable. The social forces can not only undertake government outsourcing services as the main body of capital, but also act as independent social forces to monitor the operation of the government and enterprises together with the people and promote Continuous improvement of town operating mechanism and management services. In summary, in the operation of characteristic towns, the policy tools that can be applied mainly include: regulation and deregulation, franchising, privatization, user payment, government purchase, social forces, and public participation.

\subsection{Policy Tools in Investment and Financing of Characteristic Towns}

In the construction of characteristic towns, we must take the road of innovation combining industry and finance, with characteristic industries as the engine, and finance as the driving force. Industry depends on finance, finance supports industrial development, and industry and finance interact. Characteristic towns have an inexhaustible sustainable development power. The policy tools that can be selected in the investment and financing of characteristic towns are as follows: First, bonds: as a debt certificate issued to funders for financing and promising to pay interest and repay the principal within a certain period, government bonds have high security, Features of strong liquidity, stable income and tax-free treatment. Local governments can issue certain government bonds to raise funds for the construction of public infrastructure in characteristic towns. The second is the fund: the development of characteristic industries in characteristic towns is inseparable from the support of industrial funds. There are three main modes of operation of industrial funds: one is the government-led mode, initiated by the government, and jointly invested by banks and insurance institutions to establish industries Fund mother funds, financial institutions and other investors as the priority investors, the risk is relatively small, the government as the inferior investors, bear the main risks. Second, financial institutions dominate. Financial institutions act as independent social capital parties or join other institutions to establish funds and invest in the construction of characteristic towns. The third type is the leading model of social enterprises. Enterprises are important promoters and bear credit and risk. In this type of model, although the government is not the investor, corporate investment projects require the government to grant franchise rights. The third is product crowdfunding, which is also an important way of financing for special towns. Compared with other financing methods, crowdfunding has more open features. Special towns can use their own special products or services as crowdfunding targets. Fourth, financial leasing: characteristic towns can use direct financial leasing, equipment financial leasing, sale and leaseback and other leasing models for financing. Fifth is PPP financing. It is a social financing method for the cooperation between the government's 
public sector and the private sector. The government selects private cooperation agencies in the development and construction of characteristic towns through bidding and other procedures. The two parties sign a cooperation agreement and follow the investment Proportionally set up SPV (special purpose company), and the government grants its franchise rights to participate in the construction, operation, management and supply of public products and services in characteristic towns. After the construction of the town is completed, the government withdraws its management rights from SPV through the purchase of public services, and the social capital is withdrawn. Sixth is the loan model, that is, characteristic towns use existing assets to make mortgage loans.

Based on the above analysis, this paper believes that the policy tools that can be used in the planning stage of characteristic towns are: deregulation, decentralization, families and communities, social organizations, public participation, contract outsourcing, etc. The policy tools that can be used in comprehensive development are: deregulation, financial allocation, contract outsourcing, public-private partnership, etc. The policy tools that can be used during the operation phase are: regulation and deregulation, franchising, privatization, user payment, government purchases, social forces, and public participation. The policy tools that can be used in investment and financing are: bonds, funds, product crowdfunding, financial leasing, PPP financing, etc.

\section{Conclusion}

Characteristic towns are important measures to promote economic transformation and upgrading and rural revitalization in accordance with the concept of innovation, coordination, green, openness and shared development in the context of my country's new urbanization. Characteristic towns have their unique missions and construction goals. In terms of planning, development, operation, investment and financing, they will reflect different governance concepts, governance mechanisms, and governance structures from ordinary small towns, rural communities, and cities. The effective governance of characteristic towns and the achievement of national policy goals depend on the selection and application of effective governance or policy tools. Appropriate governance or policy tools can build a communication bridge between policy objectives and policy results, promote effective implementation of policy programs, smooth implementation of policy implementation, and effective achievement of policy objectives. Tool is a method and means. It has accumulated many effective governance tools in thousands of years of human social governance practice. It has also played an extremely important role in a specific period. From the perspective of instrumentalism, there is no distinction between good and bad, only the difference between suitable and unsuitable. Each tool has its characteristics, scope of application, and advantages and disadvantages. Therefore, the choice of policy tools is more important than the policy tools themselves. The choice of policy tools will be affected by many factors such as the policy environment, policy ob- 
jectives, policy objects, governance structure, and tool characteristics. This paper divides the four types of policy tools, including government, market, society, and hybrid, from the perspective of different policy undertaking subjects. And on the basis of building a policy toolbox, a policy tool selection model is constructed, which is conducive to selecting appropriate governance tools for different governance objects and governance needs. Special towns have different characteristics in planning, comprehensive development, operation, investment and financing, etc. You can choose different policy tools, either a single tool under the same type or a combination of multiple tools, or under different types Optimized combination of multiple tools. However, no matter what policy tool is chosen, we should adhere to the principle of putting people first, create a characteristic space that is livable and industry-friendly, and improve the people's sense of gain and happiness.

\section{Fund}

Research achievements of the key project of Sichuan University of Arts and Sciences, "Precision Research on Social Governance in Characteristic Towns in Dazhou City-Perspective of Policy Tools" (2017KR001Z).

\section{Conflicts of Interest}

The authors declare no conflicts of interest regarding the publication of this paper.

\section{References}

Chen, Q. Y. (2011). Public Policy Analysis (p. 81, 82). Beijing: Peking University Press.

Chen, Z. M. (2004). Policy Science (p. 172, 170, 193, 195). Beijing: Renmin University of China Press.

Chen, Z. M., \& Xue, L. (2007). The Key Areas and Themes of Chinese Public Management Theory Research. Chinese Social Sciences, No. 3, 140-152.

Feng, K., \& Huang, X. Y. (2016). Accurately Grasp the Policy Focus of Promoting the Development of Characteristic Towns-Inspirations of Promoting the Development of Characteristic Towns in Zhejiang and Other Places. China Development Observation, No. 18, 15-18.

Howlett, M., \& Ramesh, M. (1995). Studying Public Policy: Policy Cycles and Policy Subsystems (p. 163). Oxford: Oxford University Press.

$\mathrm{Hu}, \mathrm{X}$. W. (2017). Rethinking the Development Concept and Governance Logic of Characteristic Towns. National Governance, No. 2, 28-34.

Jessop, B. (1999). The Rise of Governance and the Risk of Failure: A Case Study of Economic Development. International Social Sciences (Chinese Edition), No. 2, 32.

Lin, F. (2017). How to Operate a Characteristic Town under the Market Mechanism. China Culture News, 2017-05-06.

Liu, J. H. (2017). How to Implement Refined Social Governance in Characteristic Towns. Zhongshan Daily, 2017-7-24.

Min, X. Q. (2016). Characteristic Towns and Their Creation Path from the Perspective of 
Precise Governance. Journal of Tongji University (Social Science Edition), No. 5, 55-59.

Peters, B. G., \& Van Nispen, F. K. M. (1998). Public Policy Instruments (p. 46). Cheltenham: Edward Elgar.

Shi, Y. G. (2017). The Current Function and Path Innovation of My Country's Characteristic Towns. National Governance, No. 2, 18-27.

Xie, W. W., \& Zhu, Z. G. (2016). Institutional and Policy Innovation for the Creation of Characteristic Towns-Taking Yuhuang Shannan Fund Town as an Example. Zhejiang Finance, No. 9, 69-74.

Yao, S. J. (2017). Confluence of Governance in the Integration of Urban and Rural AreasPolicy Issues Based on “Characteristic Towns”. Social Science Research, No. 1, 45-50.

Zhang, C. F., \& Dang, X. Y. (2007). Public Administration (p. 62). Beijing: Renmin University of China Press.

Zhang, H. Y., \& Zhang, H. X. (2016). Research on the Establishment of Characteristic Towns in Zhejiang Province under the Policy Guidance-Taking Leshui Town in Chun'an County as an Example. City, No. 8, 52-55.

Zhou, L. P., \& Zhang, L. Y. (2018). Research on Land First-Level Development Model. Urban and Rural Construction, No. 16, 36.

Zhuo, Y. L. (2016). A Major Initiative to Innovate the Government's Public Policy Supply-A Theoretical Analysis Based on the Planning and Construction of Characteristic Towns. Zhejiang Social Sciences, No. 3, 32-36. 